\title{
The Effect of Painting on Emotion, Anxiety and Blood Cell (CBC) Regulation in Children with Cancer
}

\author{
Maryam Pourkhormshahi ${ }^{1}$, Saeed Teymouri ${ }^{2 *}$
}

1. Master student of Psychology, Torbatjam Branch, Islamic Azad University, Torbatjam, Iran

2. Associate Professor, Department of Psychology, Torbatjam Branch, Islamic Azad University, Torbatjam, Iran

\begin{tabular}{|c|c|}
\hline Article Info & ABSTRACT \\
\hline $\begin{array}{l}\text { Received: 2020/09/02; } \\
\text { Accepted: 2021/03/06; } \\
\text { Published Online: 2021/09/21 } \\
\text { doi } 10.30699 \text { /ainmc } 29.3 .201\end{array}$ & $\begin{array}{l}\text { Introduction: Diagnosis of cancer can cause significant psychological stress for the } \\
\text { individuals and their family. Research shows social support has a positive and significant } \\
\text { relationship with cellular immunity variables and some variables of blood cell count. Using tools } \\
\text { such as painting, a child experiences all the issues of his life, tests and builds himself. The aim of } \\
\text { this study was to evaluate the effectiveness of painting on cognitive regulation of emotion, } \\
\text { anxiety and blood cells (CBC) in children aged } 7 \text { to } 12 \text { years with cancer. }\end{array}$ \\
\hline
\end{tabular}

Methods: This research was conducted for 2 months from May 2016. The research method was quasi-experimental with pre- and post-test design and a control group. Among 43 children aged 7 to 12 years with cancer who referred to Dr. Sheikh Hospital in Mashhad and volunteered to cooperate with the study, 30 were selected according to the entry and exit criteria and were randomly assigned to the experimental and control groups. Then painting and free therapy were performed in the subjects of the experimental group. Garnfsky et al. (2001) Emotion Regulation Questionnaire, Spence Children's Anxiety Scale (SCAS) and blood cell count test were used to collect data in pre- and post-test. Analysis of covariance was used to analyze the data.

Results: Findings show that painting therapy is based on emotion regulation $(\mathrm{F}=293.8 ; P$ value $=0.001)$, anxiety $(\mathrm{F}=135.3 ; P$ value $=0.001)$, blood cell count test in $\mathrm{WBC}(\mathrm{F}=13.2 ; P$ value $=0)$ and is effective in platelet count $(\mathrm{F}=152.77 ; P$ value $=0.001)$ in children with cancer. Performing painting therapy increases the components of emotion regulation and blood cell counting and reduces the components of anxiety.

Conclusion: The overall goal of painting therapists is to enable clients to grow and transform in a healthy and safe environment by using painting tools. Therefore, in this program, sick children are given the opportunity to express their thoughts and feelings and communicate with others. According to the research findings, this approach can be used to work with children with cancer in counseling centers, hospitals and schools.

Keywords: Free painting, Emotion regulation, Anxiety, Blood cell count, Children with cancer

Corresponding Information:

Saeed Teymouri, Associate Professor, Department of Psychology, Torbatjam Branch, Islamic Azad University, Torbatjam, Iran. Email: steimory28@yahoo.com

Copyright $\odot$ 2021, This is an original open-access article distributed under the terms of the Creative Commons Attribution-noncommercial 4.0 International License which permits copy and redistribution of the material just in noncommercial usages with proper citation.

How to Cite This Article:

Pourkhoramshahi M, Teymouri S. The Effect of Painting on Emotion, Anxiety and Blood Cell (CBC) Regulation in Children with Cancer. Avicenna J Nurs Midwifery Care. 2021; 29 (3) :201-209 
تأثير نقاشى بر تنظيم هيجان، اضطراب و سلولهاى خونى (CBC) كودكان مبتلا به سرطان بيمارستان دكتر شيخ مشهد

مريم يورخر مشاهى'، سعيد تيمورى ז"

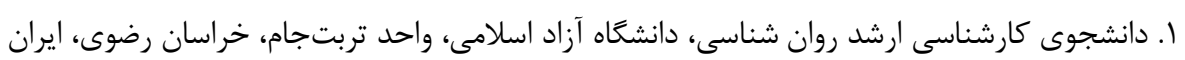

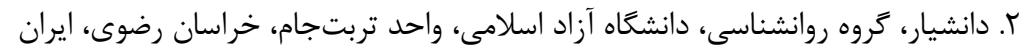

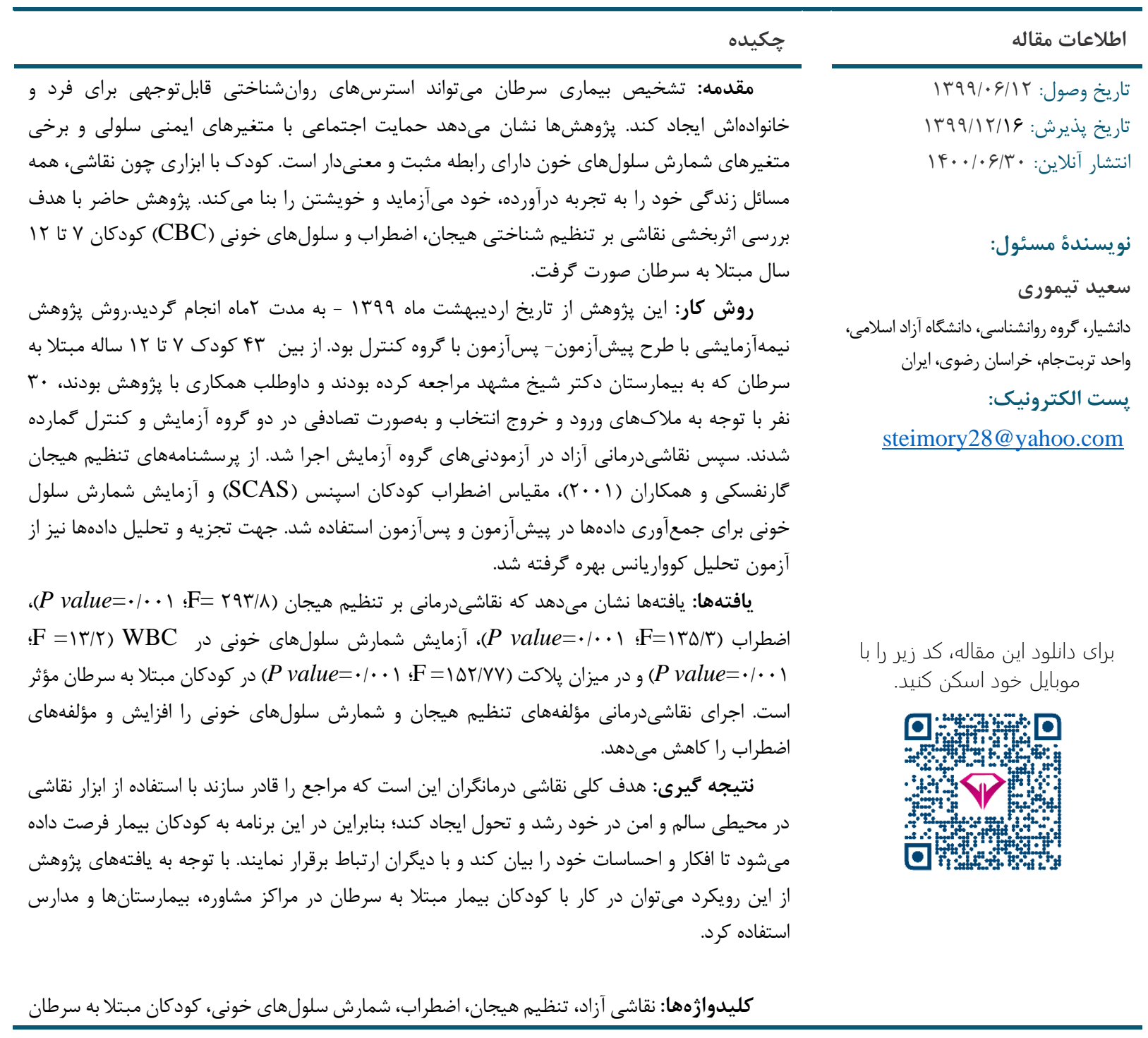

مقدمه

دختر به هسر r به [ افزايش مى يابد [r]. بهدليل طبيعت مزمن

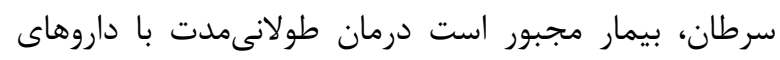

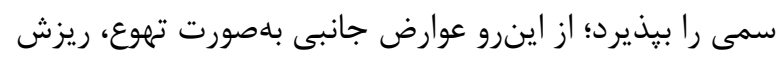

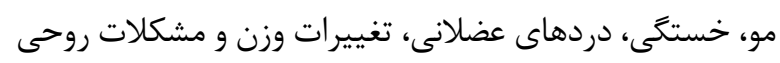

يكى از موانع موجود در مسير تحول و رشد كودكان،

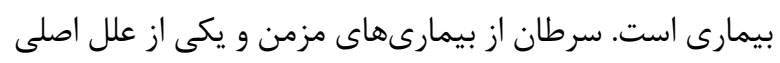

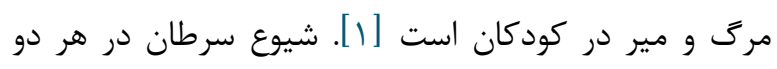

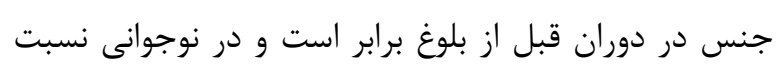


مشكلات هيجانى و رفتارى يس از رويارويى با وقايع اضطرابزا

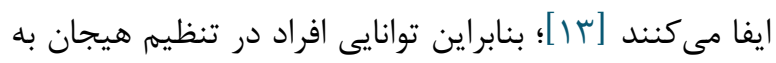

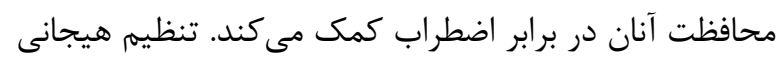

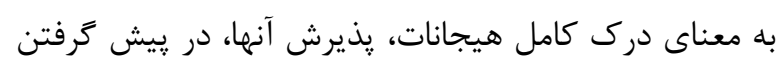

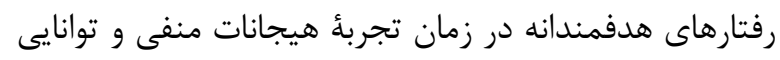

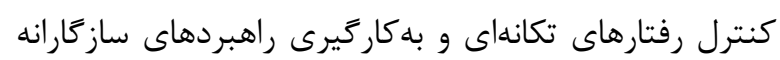

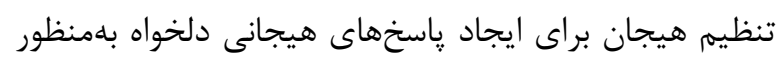

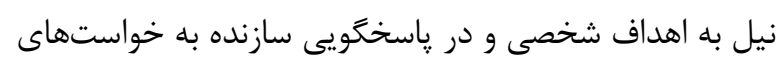

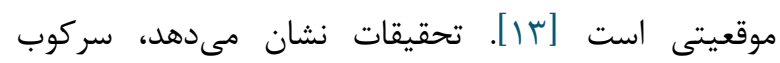

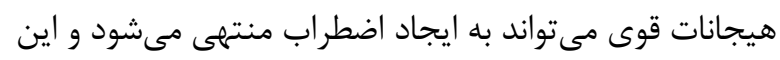

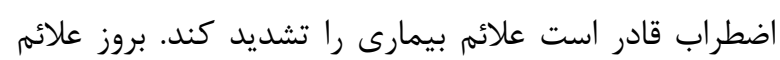

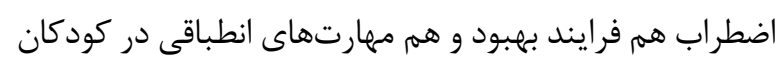

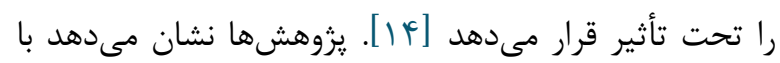
متغيرهاى ايمنى سلولى و برخى متغيرهاى شمارش سلول مانى

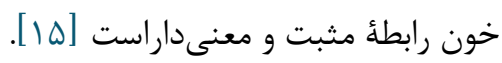

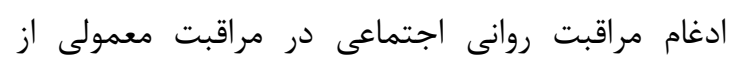

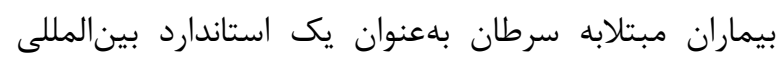

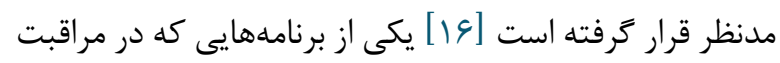

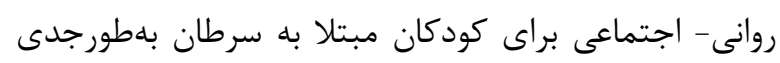

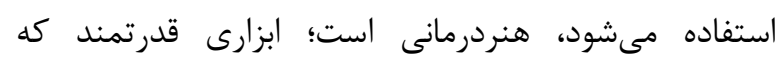

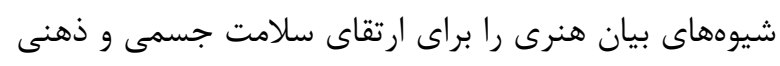

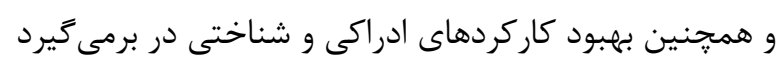

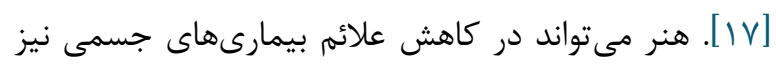

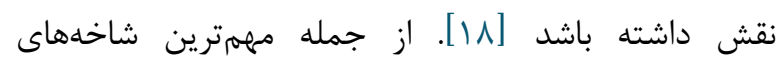
هنردرمانى، نقاشىدرمانى، يعنى ترسيم خودانكيختأ تصاوير

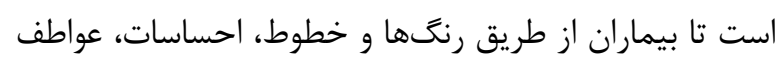

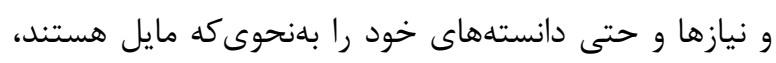

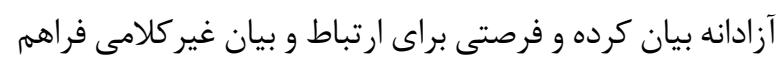

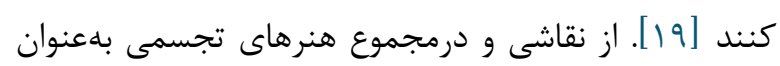

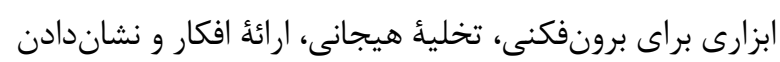

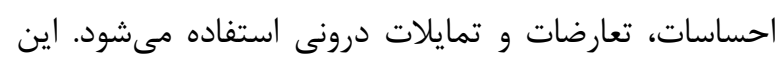
درمان موجب كاهش عواطف منفى شده [•r] و و به كودكان مبتلا به سرطان كمك مى كند احساسات عميق مخفى إنى منده

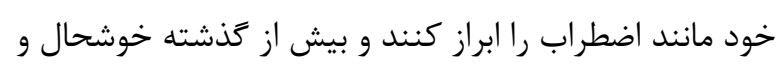

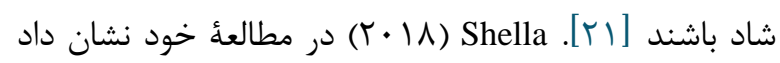

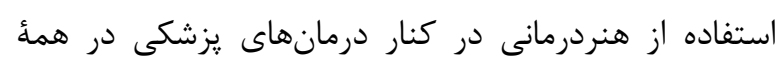

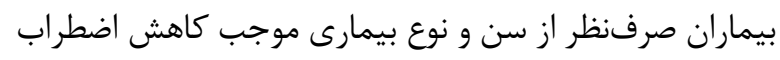

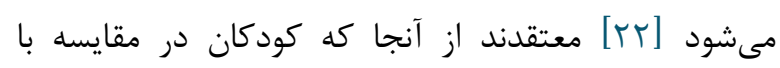

و روانى بروز مى كند [ـ]. سرطان با تغيير شكل غيرطبيعى

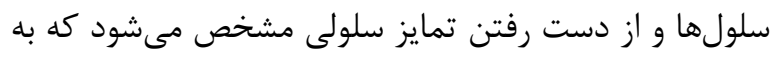

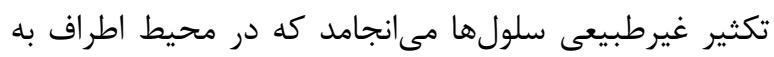

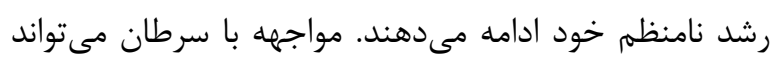

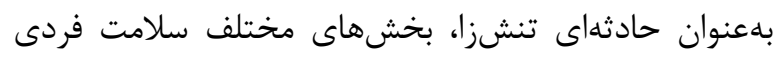

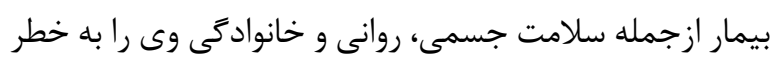

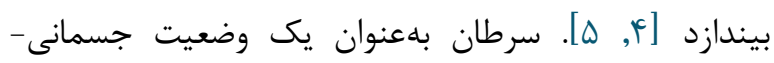

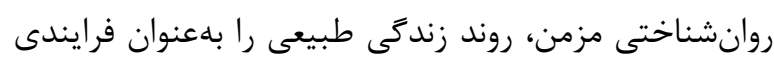

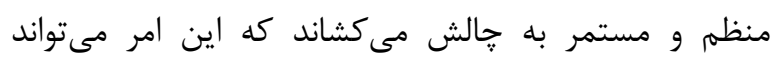

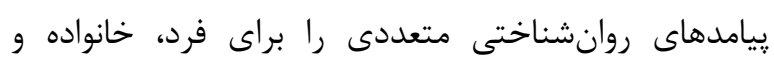

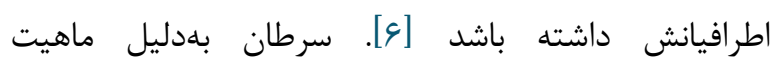

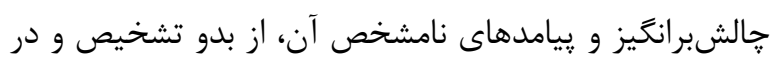

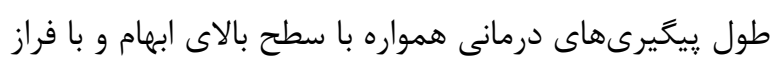

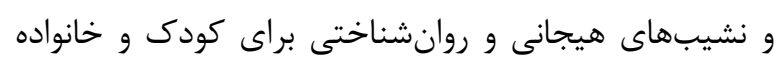

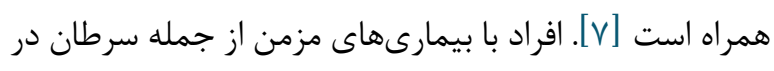

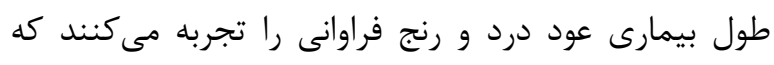

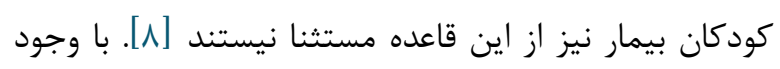

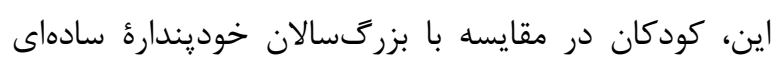

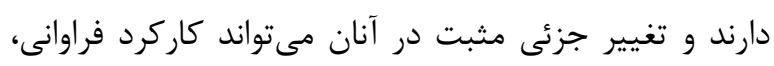

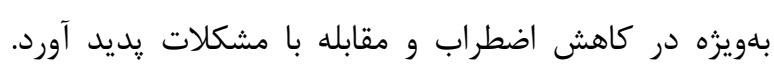

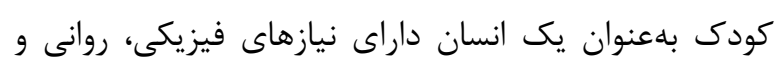

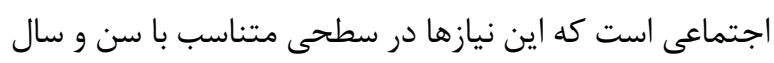
تلاش واقعى كودى و خانواده بهطور طبيعى بررسى و ارضا داري

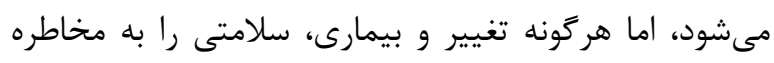

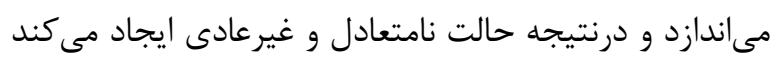

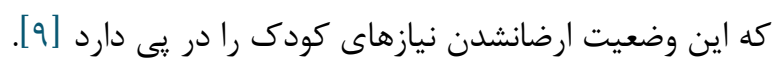

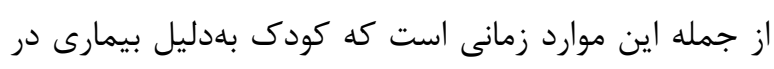

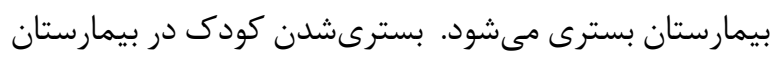

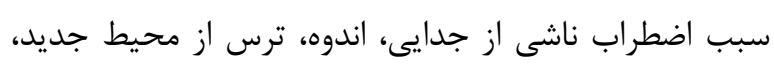

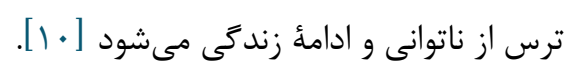

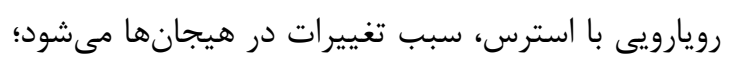

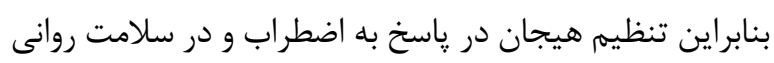

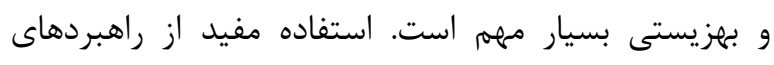

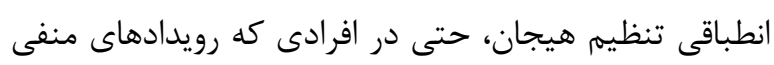

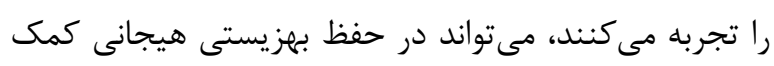

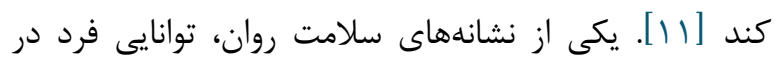

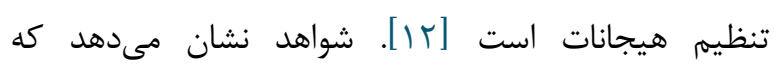
راهبردهاى تنظيم شناختى هيجان نقش مهمى در حل

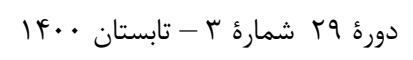




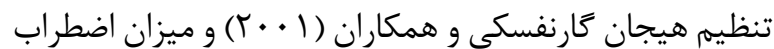
بالايى را در يرسشنامة اضطراب كودكان اسينس (SCAS) كزارش كردند، انتخاب شدند. از افراد دردسترس كه بَ بع نفر

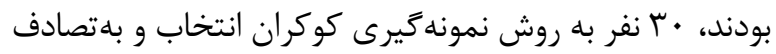
در دو گروه ها نفرى آزمايش و كنترل جايكذارى شدند. در برد

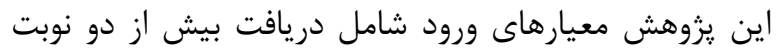

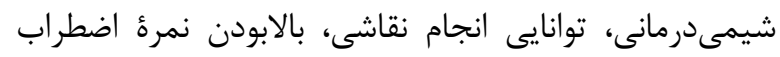

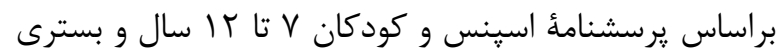

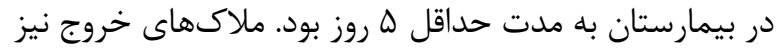
شامل بدحالشدن كودى در حين مداخله، همكارىنكردن

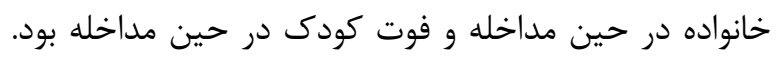
سيس اعضاى كروه آزمايش نقاشىدرمانى را دريافت كرد كردند؛

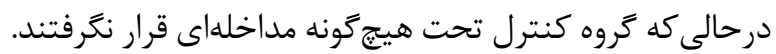

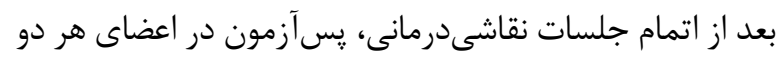

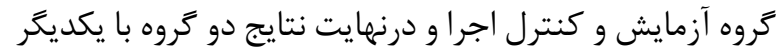
مقايسه شد. براى تجزيه و تحليل اطلاعات و آزمون فرضيهها

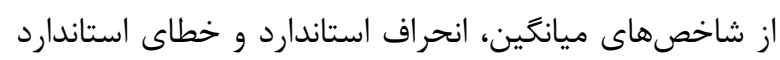
استفاده و در بخش آمار استنباطى از آزمون تحليل كوواريانس آنساف آنسائ קندمتغيره (MANCOVA) استفاده شد. همجنين براى انجام عمليات آمارى مذكور از نرمافزار (CSS Inc., ) SPSS

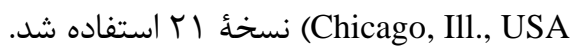

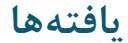

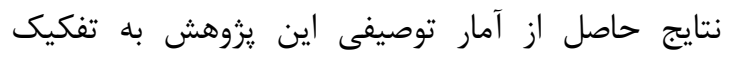

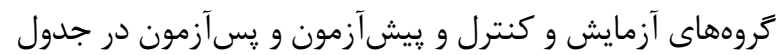

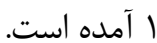

بزرگسالان، خزانهٔ لغات محدودى براى بيان تجارب هيجانى

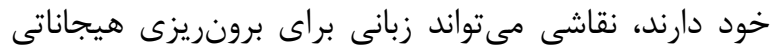

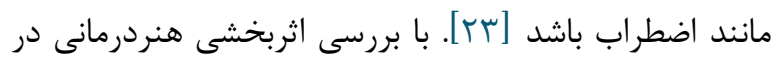

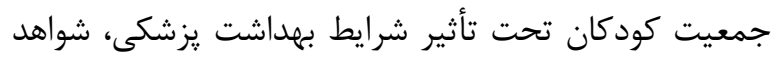

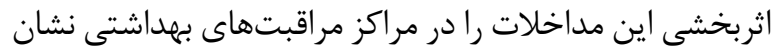

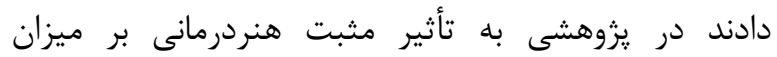

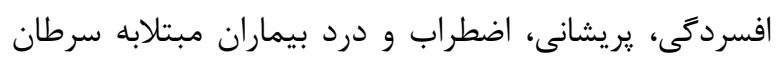

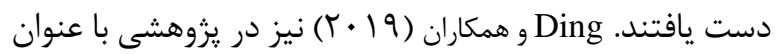
نقاشى درمانى در مراقبت از سرطان نشان دادند نقاشى درمانى دانى

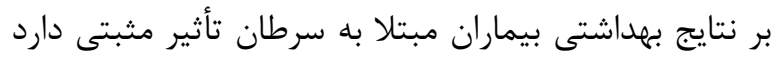

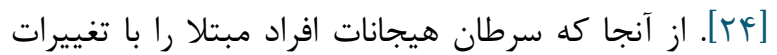

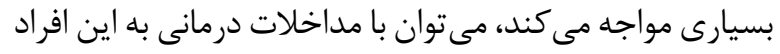

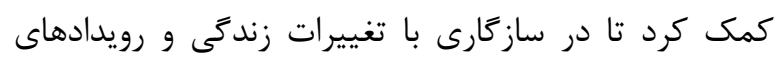

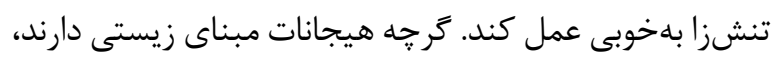

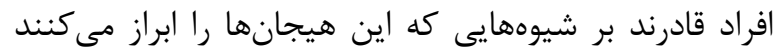

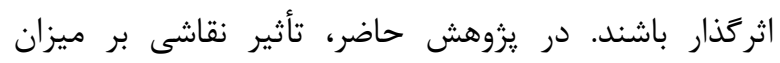

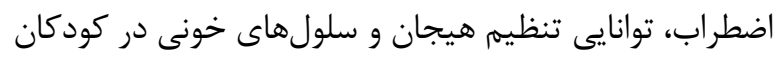
مبتلا به سرطان بررسى شده است.

$$
\text { روش كار }
$$

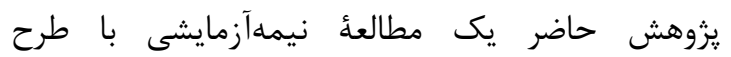

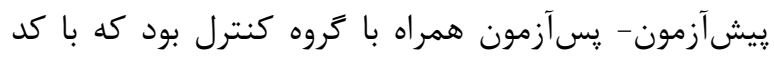

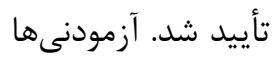
اخلاق

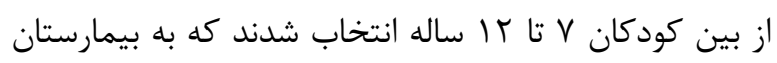

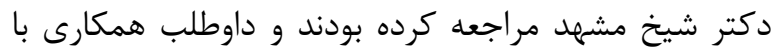

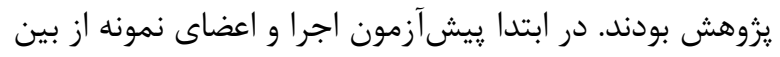

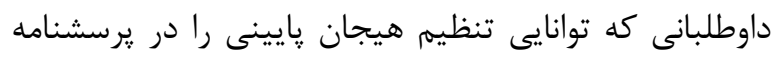

جدول ا. ميانكين و انحراف استاندارد متغيرهاى يزوهش به تفكيك تروهها در بيش آزمون و بس آزمون

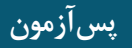

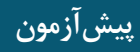

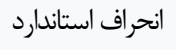

RTrm/A
ميانگين

1.1/9V

va

IT/QTH

Irm/F

Q/9

r/91

rMAG9
انحراف استاندارد

G/V

Nr

$4 / 9$

$r / Q$

$r / T$

$r / 9$

rTQ9
ميانگين

$\Lambda$

NI/AT

$\mid r Y / A$

Irr/gV

r

4

$19 .$.
آزمايش

كنترل

آزمايش

كنترل

آزمايش

كنترل

آزمايش
تنظيم هيجان

اضطراب

WBC

PLT 


\begin{tabular}{|c|c|c|c|c|c|}
\hline \multicolumn{2}{|c|}{ يسآزمون } & \multicolumn{2}{|c|}{ بيش آزمون } & تروه & متغير تروه \\
\hline$F V \cdot r / q$ & IVATr & $\Delta F \Delta$. & INFGS & كنترل & \multirow{3}{*}{ 'Hb } \\
\hline I/VD & $1 \cdot / 9 V$ & $1 / \Delta$ & $11 / 1 F$ & آزمايش & \\
\hline $1 / \Delta$ & $1 \cdot 19$ & $r / 11$ & १/१ & كنترل & \\
\hline$\Delta / \cdot V$ & $T r / \Delta q$ & F/Tr & $r Y / q$ & آزمايش & \multirow{2}{*}{${ }^{r} \mathrm{HCT}$} \\
\hline F/T & 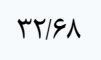 & $91 \cdot 9$ & $r \cdot / \cdot V$ & كنترل & \\
\hline$F / \mathscr{A}$ & $\Lambda \% / \wedge$ & $F / E V$ & $\Lambda T / 9 \Delta$ & آزمايش & \multirow{2}{*}{${ }^{r} \mathrm{MCV}$} \\
\hline$f / 4 \varphi$ & $\Lambda I / \Delta F$ & $\Delta / V \Psi$ & $1 \cdot / 9$ & كنترل & \\
\hline$r / r$ & rA & $1 / 9 V$ & ru & آزمايش & \multirow{2}{*}{$\mathrm{MCH}^{4}$} \\
\hline $1 / 49$ & $r V / \Lambda \Lambda$ & T/YF & TE/FT & كنترل & \\
\hline $1 / r$ & $M T / g V$ & $1 / \cdot V$ & D & آزمايش & \multirow{2}{*}{${ }^{\circledR} \mathrm{MCHC}$} \\
\hline . 194 & שr/wr & $1 / \cdot \Delta$ & TT/VA & كنترل & \\
\hline
\end{tabular}

$$
\begin{aligned}
& \text { مقادير احتمال بهدستآمده در تمام اثرات تعاملى متغيرها در }
\end{aligned}
$$

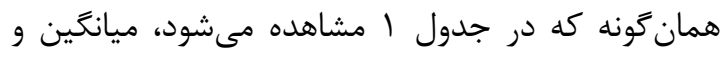

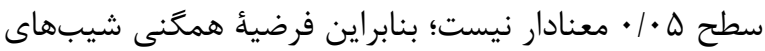

$$
\begin{aligned}
& \text { انحراف استاندارد تنظيم هيجان، اضطراب و آزمايش شمارش }
\end{aligned}
$$

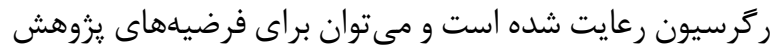

$$
\begin{aligned}
& \text { سلول خونى در كروه آزمايش، تغييرات بيشترى داشته است. } \\
& \text { از روش تحليل كوواريانس استفاده كرد. }
\end{aligned}
$$

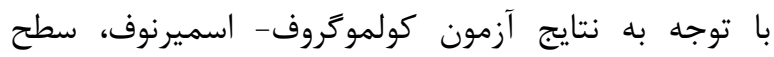

$$
\begin{aligned}
& \text { بلمنظور بررسى اثر نقاشىدرمانى، تحليل كوواريانس }
\end{aligned}
$$

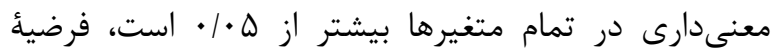

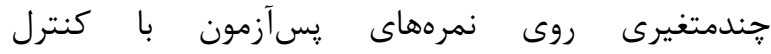

$$
\begin{aligned}
& \text { نرمالبودن محقق شده است. براى بررسى همخَى واريانسها } \\
& \text { ييشآزمونهاى متغيرهاى وابسته انجام شد. }
\end{aligned}
$$

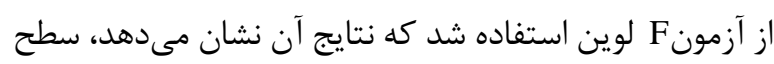

\begin{tabular}{|c|c|c|c|c|c|c|}
\hline ضريب اتا & مقدار احتمال & خطاى درجه آزادى & درجه آزادى فرضيه & $F$ & مقدار & تروه \\
\hline.$/ 9 F V$ & $\% \cdots$ & rI & f & $9 \% / 9$ & $\cdot / 9 \Delta$ & اثر پِيلايى \\
\hline
\end{tabular}

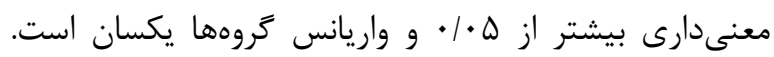

جدول r. تحليل كوواريانس جندمتغيرى روى ميانكَين يس آزمون متغيرها در كروهها با كنترل يِيش آزمون

جدول س. نتايج تحليل كوواريانس تكمتغيرى بر متغيرهاى وابسته

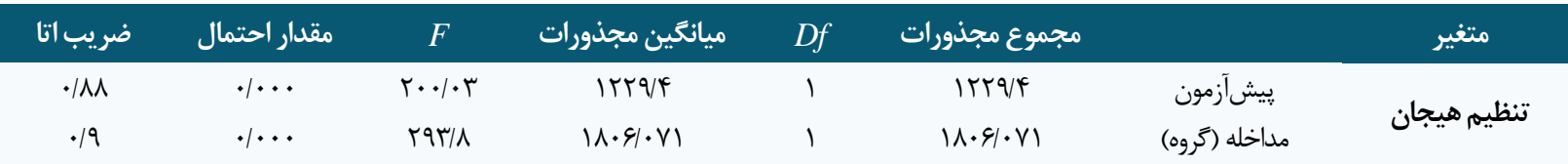

\footnotetext{
1. Hemoglobin

2. Hematocrit

${ }^{3}$. Mean Cell Volume

${ }^{4}$. Mean Cell Hemoglobin

5. Mean Cell Hemoglobin Concentration
}

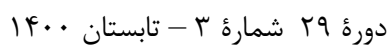


4. F تأثير نقاشى بر تنظيم هيجان، اضطراب و سلولهاى خونى (CBC)...

\begin{tabular}{|c|c|c|c|c|c|c|c|}
\hline & & & 9110 & TV & $19 \Delta / 9$ & خطا & \\
\hline \multirow{3}{*}{$\begin{array}{l}\cdot / V \Delta \\
\cdot / \Delta T\end{array}$} & \multirow{3}{*}{$\begin{array}{l}* \cdots \\
* \cdots\end{array}$} & \multirow{3}{*}{$\begin{array}{l}\Lambda \cdot / r \\
\mid r \Delta / r\end{array}$} & TGT & 1 & TET & ييشآزمون & \multirow{3}{*}{ اضطراب } \\
\hline & & & ker/T & 1 & K\&r/T & مداخله (كروه) & \\
\hline & & & $r / T V$ & TV & $N N N^{F}$ & خطا & \\
\hline \multirow{3}{*}{ rזr/. } & \multirow{3}{*}{$\begin{array}{l}* \ldots \\
. / \ldots\end{array}$} & \multirow{3}{*}{$\begin{array}{l}V T / r \\
\mid r / T\end{array}$} & 11910 & 1 & $119 / 0$ & يِشآزمون & \multirow{3}{*}{$W B C$} \\
\hline & & & $r \cdot / 9$ & 1 & $r \cdot / 9$ & مداخله (كروه) & \\
\hline & & & $1 / 9$ & TV & $F r / q$ & خطا & \\
\hline \multirow{3}{*}{$\begin{array}{l}. / 9 T \\
. / \Lambda \Delta\end{array}$} & \multirow{3}{*}{$\begin{array}{l}* / \ldots \\
. / \ldots\end{array}$} & \multirow{3}{*}{$\begin{array}{l}r \cdot N q \\
\mid Q T / V V\end{array}$} & $\Delta T \Delta \Delta H \cdot \Delta S G$ & 1 & $\Delta T \Delta \Delta T \cdot \Delta G G$ & بِيشآزمون & \multirow{3}{*}{ يلاكت خون } \\
\hline & & & $r \Delta \& \Lambda \cdot V \& q q$ & 1 & $r \Delta \& \Lambda \cdot V F q 9$ & مداخله (كروه) & \\
\hline & & & IV.ITrV & TV & roqrql... & خطا & \\
\hline
\end{tabular}

وقتى افراد در فعاليتهايى شركت مىكنند كه از آن لذت

با توجه به مقادير جدول ^َ بين گروه كنترل و آزمايش در مىبرند، فاكتورهاى فيزيولوزيك آنان مانند فشار خون، ضربان

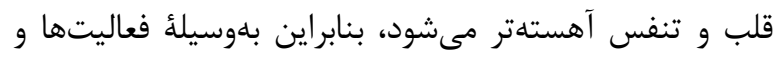

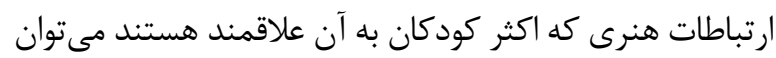
كنشهايى را در فيزيولوزى و بيولوزى فرد فعال كرد كه آن كنشها توان مقابله فرد در برابر بيمارىها را بالا برده و روى رئ سيستم ايمنى او تأثير بحذارند. با توجه به اين كه مداخلات نقاشى درمانى بر تنظيم هيجان، كاهش سطح اضطراب و افزايش سطح سلولهاى خونى كودكان بيمارموثر واقع شد، مسئولين بيمارستانها و مراكز، جهت

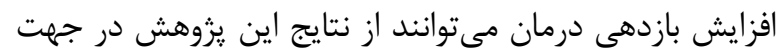
بهبود شرايط روحى و جسمى كودكان سرطانى استفاده كنند.

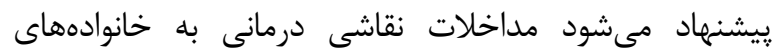
كودكان بيمار براى انجام در منزل، افراد شاغل در حرفه مرتبط

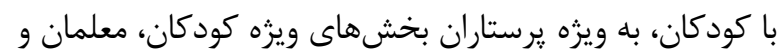
ساير مربيان اين كودكان اموزش داده شود. حضور هنردرمانكر در كنار تيم يزشكى مىتواند موثر واقع شود. جلسات دردان موردان

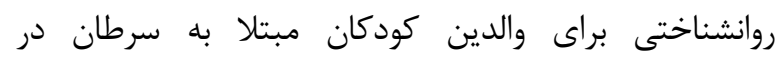
بيمارستانها و مراكز درمانى جهت كنترل اضطراب، افسردكى و و ساير مشكلات روحى بركزار شود.

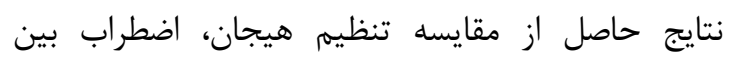
كروههاى آزمايش و كنترل يس از حذف اثر يِيش آزمون، نشان

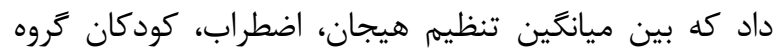
آزمايش و كروه كنترل در مرحله پِ يس آزمون (P value>0.01)

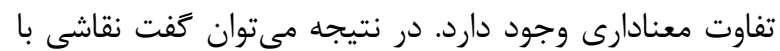

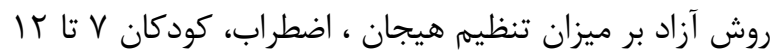
ساله مبتلا به سرطان تاثيرات مثبتى دارد. تمامى مؤلفهها تفاوت معنى دارى وجود دارد؛ به عبارت ديكر بارئر نقاشىدمانى سبب افزايش توان تنظيم هيجان، كاهش وجن

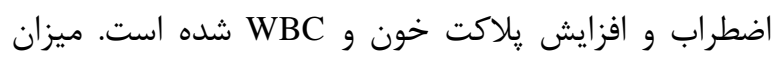

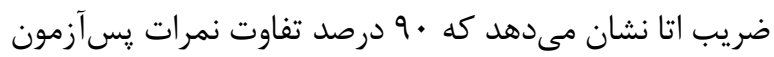

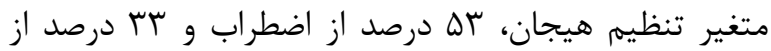

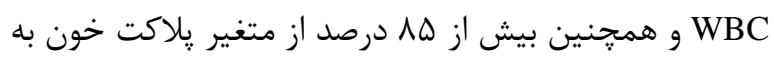
تأثير نقاشىدرمانى مربوط است.

$$
\text { بحث و نتيجه تيرى }
$$

نقاشى و تجسم، انعكاس افكار و نارضايتى هاى درئ درونى كودى نسبت به محيط پيرامون است كه كودى با استفاده از

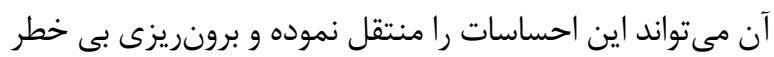

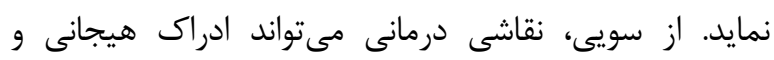

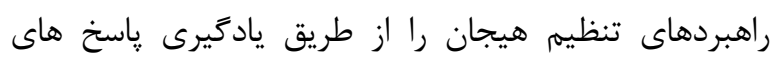

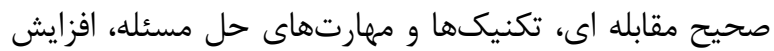
احساس تعلق و ارائه در يك محيط بيمارستانى ممكن است فرد

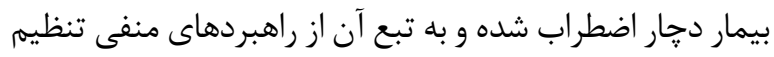

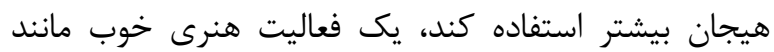
نقاشى مىتواند تا حد زيادى در كنترل و كاهش اين حالات

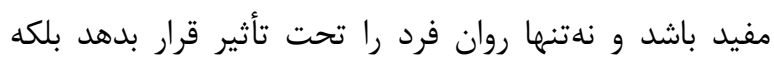
بلهورت مستقيم و غير مستقيم روى جسم همم اثر بحذارد.

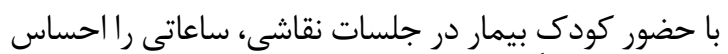

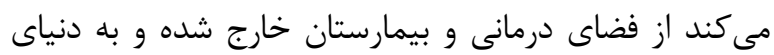
كودكى خود كه به سبب بيمارى مدتى از آن آن فاصله داشتهانه برمى گردد. اين جلسات موجب شد شور و شوق و ارامش خاطر

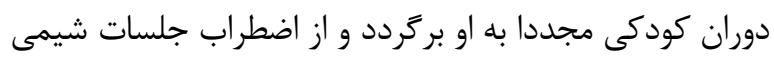
درمانى فاصله بخيرد. 
خودينداره و توانايى تنظيم هيجانى آنها را بالا مىبرد [بس].

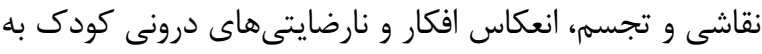

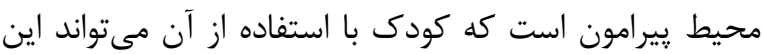

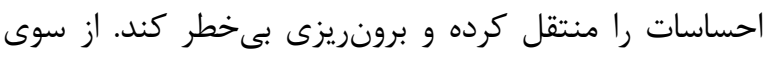

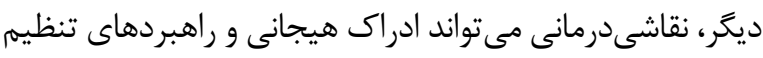
هيجان را از طريق يادكيرى ياسخهاى صحيح مقابلهاى،

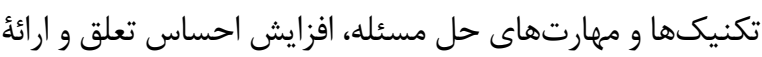

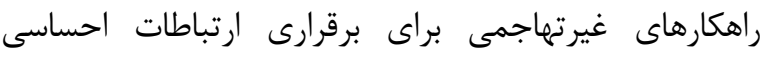

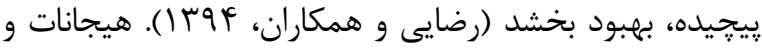

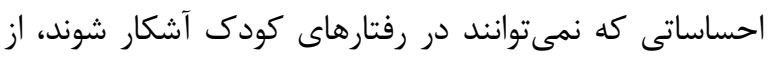

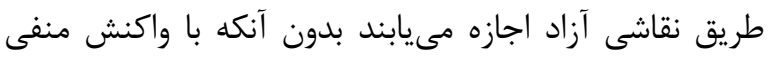

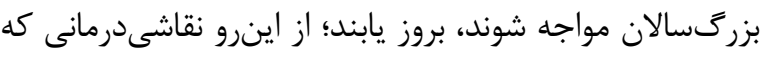

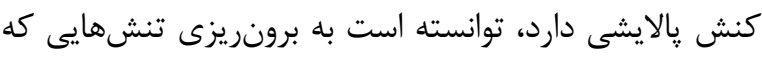

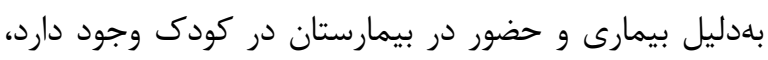

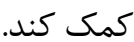
آموزش راهبردهاى تنظيم هيجان به كودكان مبتلا به

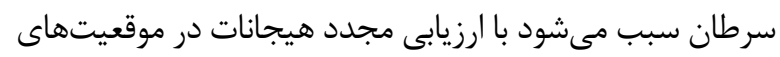

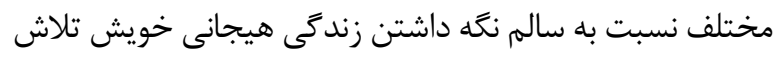

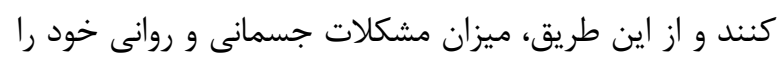
كاهش دهند. يافتهها نشان مى دهد شركت در اين اين برنان

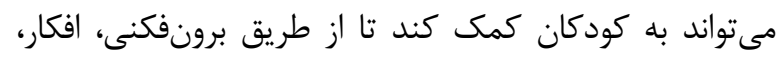
هيجانها و احساسات خود را ابراز كنند و درنتيجه به تنظيم

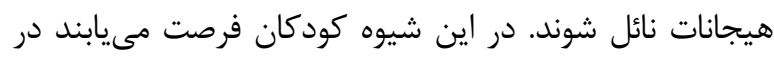

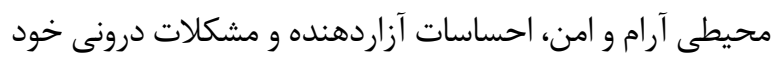

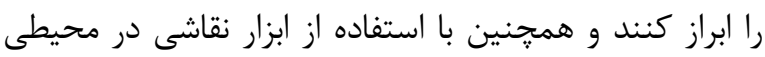

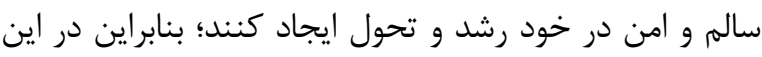

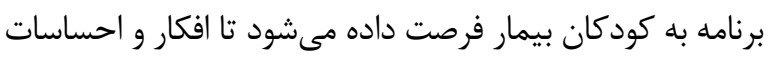

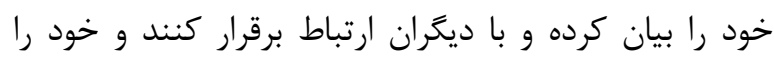
بهكونهاى متفاوت بشناسند و درك كنند.

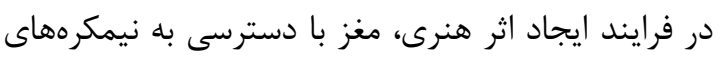

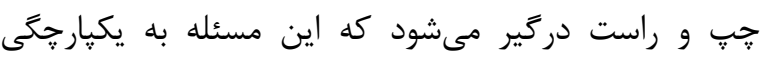

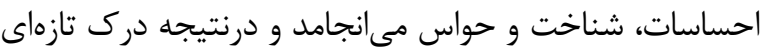

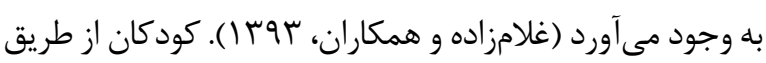

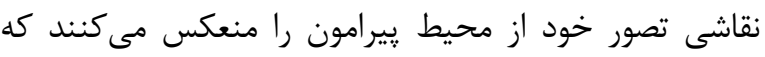
بخشى از اين تصورات مىتواند بيانكر اضطرابها و نتخرانى آنهاى

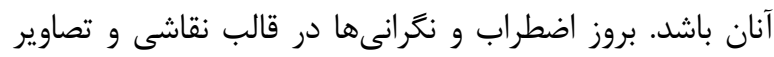

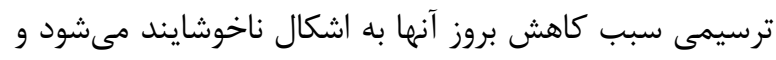
در بيان احساسات به عنوان ابزار غير كلامى كمك مى كند.

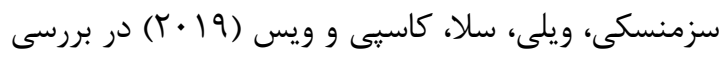
تاثير هنر درمانى (REPAT) در بيماران مبتلا به سرطان إنان

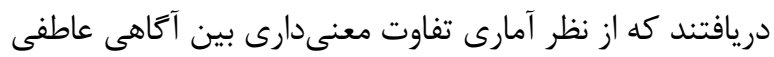

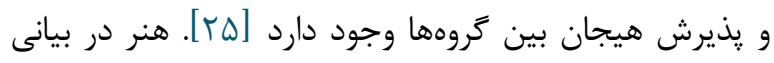
جذاب و نمادين به كونه اي غير مستقيم تصور كودكان را در دران

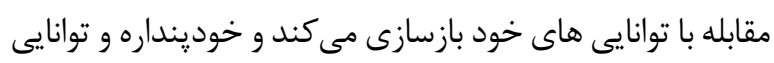

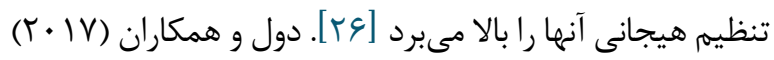
ارزيابى هنر درمانى بر ميزان خلق و خو، اضطراب و درد درد بيماران مبتلا به سرطان تحت شيمى درمانى، به نتيجه مشابه با بان

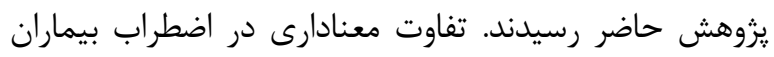

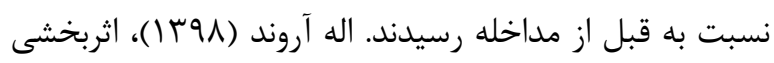

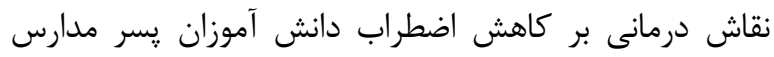

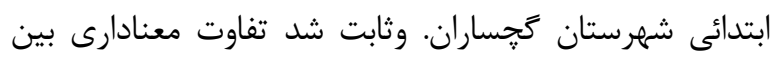

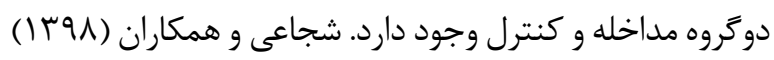
ي[rV]

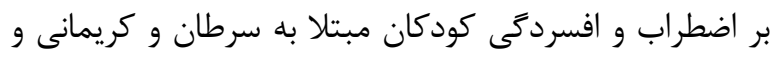

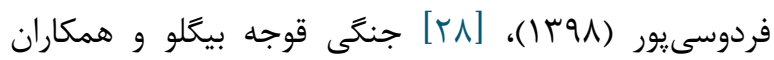

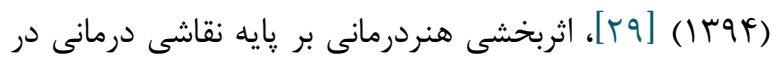

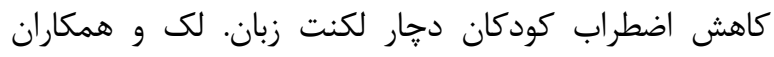

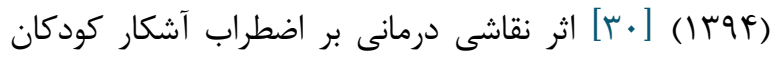

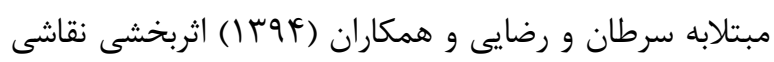
درمانى بر كاهش اضطراب و يرخاشكَرى دانش آموزان دبستانى دانى

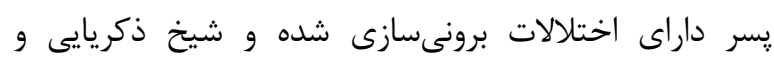

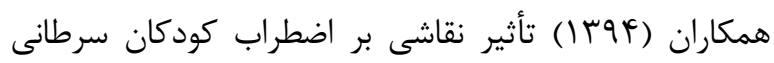

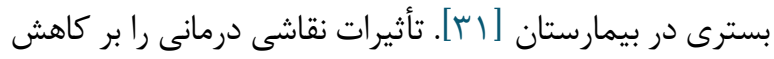

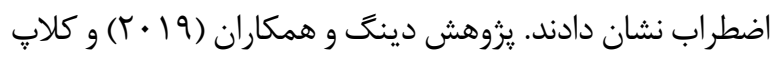

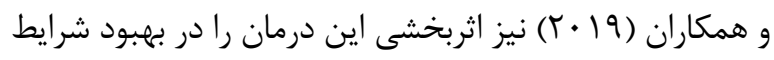

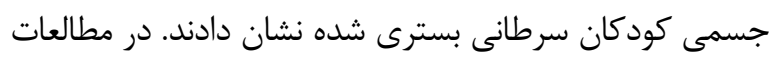
ذكر شده نيز نتيجه مشابهى كزارش شده مدان مبنى برى اينكه اضطراب

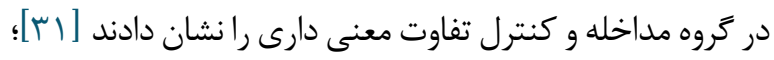

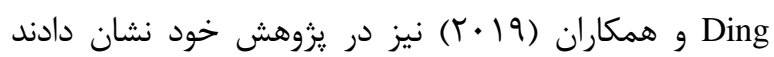

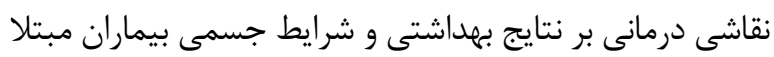

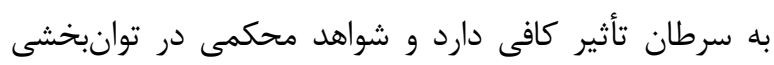

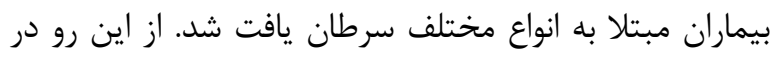

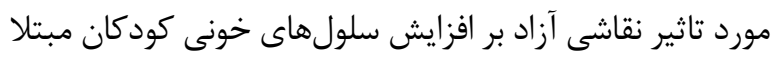

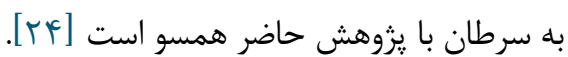
هنر در بيانى جذاب و نمادين بهَكونهاى غيرمستقيم تصور

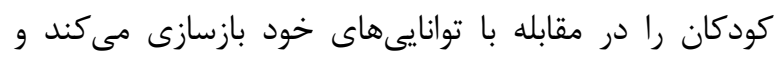

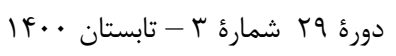




$$
\text { منار ميان نويسند دران هيجز تعارضى در منافع يافت نشد. }
$$

\section{References}

1. Pryce-Jones J. Happiness at work: Maximizing your psychological capital for success: John Wiley \& Sons; 2011.

2. Kaye EC, Jerkins J, Gushue CA, DeMarsh S, Sykes A, Lu Z, et al. Predictors of Late Palliative Care Referral in Children With Cancer. J Pain Symptom Manage. 2018;55(6):1550-6 [DOI:10.1016/j.jpainsymman.2018.01.021] [PMID] [PMCID]

3. Delgado-Guay MO, Hui D, Parsons HA, Govan K, De la Cruz M, Thorney S, et al. Spirituality, religiosity, and spiritual pain in advanced cancer patients. J Pain Symptom Manage. 2011;41(6):986-94.

[DOI:10.1016/j.jpainsymman.2010.09.017] [PMID]

4. Besharat M, Zamani Froshani N, Moafi A. The mediating role of cognitive emotion regulation strategies on the relationship between personality characteristics and psychological distress in siblings of children with cancer. J Psychol Sci. 2017;16(62):179-97.

5. Buono R, Longo VD. Starvation, stress resistance, and cancer. Trends Endocrinol Metab. 2018;29(4):271-80.

[DOI:10.1016/j.tem.2018.01.008]

[PMID] [PMCID]

6. Adili D, Bahrami Ehsan H, Shahi F, Mirzania M. Dimensions of quality of life in women with breast cancer under chemotherapy and its relation with demographic characteristics. J Psychol Sci. 2018;17(67):345-50.

7. Muscara F, McCarthy MC, Woolf C, Hearps SJ, Burke K, Anderson VA. Early psychological reactions in parents of children with a life threatening illness within a pediatric hospital setting. Eur Psychiatry. 2015;30(5):555-61. [DOI:10.1016/j.eurpsy.2014.12.008] [PMID]

8. Ozkan S, Ozkan M, Armay Z. Cultural meaning of cancer suffering. J Pediatr Hematol Oncol. 2011;33 Suppl 2:S102-4 [DOI:10.1097/MPH.0b013e318230db09] [PMID]

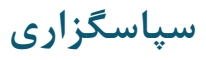

بدين وسيله از مسئولين وكارمندان محترم بيمارستان

دكتر شيخ مشهد به خصوص بخش انكولوزى و همجنين از

جناب آقاى دكتر كاشانى، استاد فرزانه و ارجمندم كه در اين بـن

يزوهش بدون هيج جشمداشتى از ابتداى طرح همراه اينجانب

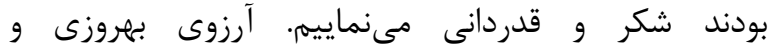

سعادتمندى براى همر اهان اين يزوهش راسى خواستاريم.

9. Hockenberry MJ, Wilson D. Wong's Nursing Care of Infants and Children. 9 ed: Elsevier eBook on VitalSource; 2011.

10. MARLOW DR. Textbook of Pediatric Nursing. MCN: Am J Maternal/Child Nurs. 1979;4(1):1656. [DOI:10.1097/00005721-197901000-00007]

11. Doll M, Roshon SG, Stone ER, Butler RS Evaluation of art therapy on mood, anxiety, and pain levels in patients with cancer undergoing chemotherapy treatment. J Clin Oncol. 2017;35(15_suppl):e21713-e. [DOI:10.1200/JCO.2017.35.15_suppl.e21713]

12. Aldao A, Nolen-Hoeksema S, Schweizer S Emotion-regulation strategies across psychopathology: A meta-analytic review. Clin Psychol Rev. 2010;30(2):217-37. [DOI:10.1016/j.cpr.2009.11.004] [PMID]

13. Brody AC, Simmons LA. Family Resiliency During Childhood Cancer: The Father's Perspective. J Pediatr Oncol Nurs. 2007;24(3):15265. [DOI:10.1177/1043454206298844] [PMID]

14. Li WH, Chung OK. Enhancing the efficacy of psychoeducational interventions for paediatric patients in a randomised controlled trial: methodological considerations. J Clin Nurs. 2009;18(21):3013-21. [DOI:10.1111/j.13652702.2009.02913.x] [PMID]

15. Hamid N. The correlation between social support and immune system in managers of high schools of Khozestan province. J Gorgan Univ Med Sciences. 2006;8(3):29-36.

16. Brage E, Vindrola-Padros C. An ethnographic exploration of the delivery of psychosocial care to children with cancer in Argentina. Eur J Oncol Nurs. 2017;29:91-7. [DOI:10.1016/i.ejon.2017.05.002] [PMID]

17. Bilgin E, Kirca O, Ozdogan M. Art therapies in cancer - A non-negligible beauty and benefit. J Oncol Sci. 2018;4(1):47-8. [DOI:10.1016/i.jons.2017.12.003]

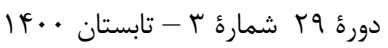

$$
\text { مجله مراقبت يرستارى و مامايى ابنسينا }
$$


18. Moschini LB. Art, play, and narrative therapy: Using metaphor to enrich your clinical practice: Routledge; 2018. [DOI:10.4324/9781351170925]

19. Rezaee S, Khodabakhshi Koolaee A, Taghvaee D. Influence of painting therapy in decreasing aggression and anxiety among elementary school boys. J Pediatr Nurs. 2015;2(2):10-9.

20. Hass-Cohen N, Bokoch R, Clyde Findlay J, Banford Witting A. A four-drawing art therapy trauma and resiliency protocol study. Arts Psychother. 2018:61:44-56 [DOI:10.1016/j.aip.2018.02.003]

21. Altay N, Kilicarslan-Toruner E, Sari C. The effect of drawing and writing technique on the anxiety level of children undergoing cancer treatment. Eur J Oncol Nurs. 2017;28:1-6 [DOI:10.1016/i.ejon.2017.02.007] [PMID]

22. Katz C, Hamama L. "Draw me everything that happened to you": Exploring children's drawings of sexual abuse. Children Youth Serv Rev. 2013;35(5):877-82.

[DOI:10.1016/j.childyouth.2013.02.007]

23. Clapp LA, Taylor EP, Di Folco S, Mackinnon VL. Effectiveness of art therapy with pediatric populations affected by medical health conditions: a systematic review. Arts Health. 2019;11(3):183201. [DOI:10.1080/17533015.2018.1443952] [PMID]

24. Ding Z, Ouyang Y, Zhang N. Painting Therapy in Cancer Care: A Descriptive Systematic Review. $\begin{array}{llll}\text { Open J 2019;9(02):89. } & \text { Nurs. }\end{array}$ [DOI:10.4236/ojn.2019.92009]

25. Czamanski-Cohen JP, Wiley JFP, Sela NB, Caspi $\mathrm{O}$ Md P, Weihs KM. The role of emotional processing in art therapy (REPAT) for breast cancer patients. J Psychosoc Oncol. 2019;37(5):586-98.

[DOI:10.1080/07347332.2019.1590491] [PMID]

26. Aron-Rubin J. The art of art therapy: what every art therapist needs to know: Routledge; 2013.

27. Golparvar M, Aghaei A, Bordbar MR. Comparing the effectiveness of group story therapy and the artplay therapy on anxiety and depression in children with cancer: based on the framework, principles and rules of cognitive-behavioral approach. Iran J Rehab Res. 2019;6(1):50-9.

28. Karimaee M, Ferdosipour A. The Effect of Painting Therapy on Reducing Signs of Symptoms in Separation Anxiety Disorder in Preschool Children. Rooyesh-e-Ravanshenasi Journal(RRJ). 2019;8(8):205-12.

29. Jangi s, Shirabadi A, Jani S, Pouresmali A Effectiveness of art Therapy Based on Painting Therapy to Reduce Anxiety of Children with Stuttering. J Ilam Univ Med Sci. 2015;23(2):53-60.

30. Goldbeck L, Ellerkamp T. A randomized controlled trial of multimodal music therapy for children with anxiety disorders. J Music Ther. 2012;49(4):395-413. [DOI:10.1093/jmt/49.4.395] [PMID]

31. Neda Sheikhzakaryaee, Golrok Moridi, Marlin Ardalan, Fardin Hododi. Effect of painting on the anxiety of hospitalized cancer children. Health Monitor J Iran Inst Health Sci Res. 2016;15(1):638 .

32. Stepney SA. Art therapy with students at risk: Fostering resilience and growth through selfexpression: Charles C Thomas Publisher; 2017. 